\title{
Performance Analysis of MANET Routing Protocols - A Comparative Study
}

\author{
Arshad Shaikh \\ Isra university \\ Hyderabad, Pakistan
}

\author{
Danish Vasan \\ Isra university \\ Hyderabad, Pakistan
}

\author{
Khalid H. Mohammadani \\ Isra university \\ Hyderabad, Pakistan
}

\begin{abstract}
Efficient routing has always been a matter of concern for mobile ad-hoc networks (MANETs). While reactive protocols are competing with the performance of proactive protocols, hybrid protocols have attempted to brew the best of the both. This paper reviews some of the selected literature regarding MANET routing protocols and studies the comparative performance of different routing protocols such as (AODV, DSR DSDV FSR, ZRP and etc.) under different scenarios (varying number of nodes, mobility, traffic type and load). The results from these papers are then compiled together and summarized in the form of graphs comparing the QoS parameters including Packet Delivery Ratio, Average End to End Delay, Average Throughput and Normalized Routing Load. The study concludes that no single protocol fit all needs. For a given scenario, a protocol may be chosen depending upon the mobility, size and required QoS.
\end{abstract}

\section{Keywords}

Mobile Ad-Hoc Network, Routing Protocol, AODV, RAODV, ERAODV DSDV, DSR, FSR, ZRP, QoS, RREQ Performance Analysis.

\section{INTRODUCTION}

In a Mobile Ad-Hoc Network [3] nodes are mobile and are connected via wireless link in an arbitrary and dynamic manner with the neighboring nodes present in their antenna ranges. The overall end to end communication is, therefore, multi-hop and the network has a highly dynamic and unstable topology. In such environments, discovery and maintenance of efficient routes is a very challenging [4-6].

Although MANET routing protocols are not new, and have remained a topic of active research and discussion for more than a decade, a current literature survey that summarizes the relative merits and de-merits of these approaches was long needed. This paper is an attempt to fill the gap.

The paper is organized as follows: Section 2 presents a brief classification of routing protocols. Section 3 gives the description of various performance metrics for these routing protocols, section 4 presents the summary of selected literature in the domain and finally section 5 concludes the paper with consolidated results of investigations present in the studied literature.

\section{ROUTING PROTOCOLS}

The routing protocols are used to find a path from source to target destination. Essentially these protocols have been classified into three categories. (1) (Proactive) routing protocols [7] [8], (2) (Reactive) routing protocols [7] [8] and (3) Hybrid routing protocols (Proactive + Reactive). [9].

\subsection{Proactive Routing Protocols}

In proactive (table-driven) protocols all nodes exchange with their neighbors information about shortest routes to other nodes periodically. After analyzing these routes they compute and store the shortest path to each possible destination in a table [6]. These types of protocols are not difficult to implements in the network but due to the resource hungry nature, limited energy of the node and slow propagation of routing information it becomes infeasible to use this protocol. DSDV (Destination Sequenced Distance-Vector) [15-16], FSR (Fisheye State Routing Protocol) [17], and CGSR (Cluster Head Gateway Switch Routing Protocol) [8] [18] are table driven (Proactive) routing protocols.

\subsection{Reactive Routing Protocols}

In contrast, reactive (on-demand) protocols do not continuously exchange routing information with the neighbors, instead a route is constructed only when it is needed. When a source node needs a route to a destination node it starts a node discovery process, in which route request messages are flooded across the network. The destination node responds to this request hence establishing a route. The Route is maintained until destination become unreachable, or source is no longer interested in destination. AODV (Ad-Hoc on Demand Distance Vector Routing Protocol) [10], DSR (Dynamic Source Routing Protocol) [11], TORA protocol (Temporary-Ordered Routing Algorithm) [12], CBRP (Cluster Based Routing Protocol) [13], these are all On Demand (Reactive) Routing Protocols.

\subsection{Hybrid Routing Protocol [33]}

Hybrid (proactive + reactive) protocols are simply the combination of two protocols stated above. ZRP (Zone Routing Protocol) [19] [9] being a typical example in which the whole topology is divided into a hierarchy of zones. Proactive routing is used locally within each zone, while reactive routing is used to create routes between the zones. All nodes within a radius of $r$ hops are considered a zone.

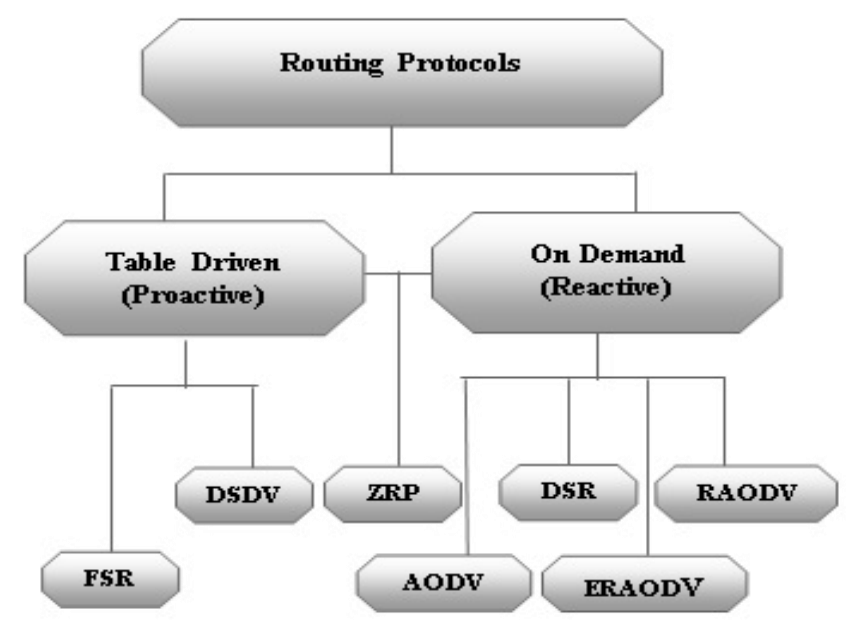

Fig 1: Classification of Routing Protocols 
Figure 1 shows a classification of MANET routing protocols such as Destination Sequence Distance Vector (DSDV), Zone Routing Protocol (ZRP) [9] [19], Ad-Hoc on Demand Distance Vector (AODV), Dynamic Source Routing (DSR), Reverse Ad-Hoc On Demand Distance Vector (RAODV) [20], Energy Reverse Ad-Hoc On Demand Distance Vector (ERAODV) [20] routing protocols.

\section{QoS PARAMETERS}

Typically, quality of service (QoS) parameters are used to define [34] the required performance of a connection or a network as described by QoS routing [21], QoS MAC [22] and resource reservation [23]. However the same parameters may be used as performance metrics to study the effectiveness of a protocol. Following are some of the important QoS parameters that have been studied in the reviewed literature.

\subsection{Packet Delivery Ratio}

Packet delivery ratio is calculated by dividing the number of packets received at the destination by the number of packets originated at the source. For the best performance packet delivery ratio of routing protocol should be as high as possible [24]. If the ratio is 1 , it will be the best delivery ratio of the routing protocol.

\subsection{Average Throughput}

It refers to the amount of data delivered in a unit of time averaged over the number of nodes [24] [25]. It is measured in bits per second (bps).

\subsection{Average End-to-End Delay}

It is the average time a packet takes to reach the destination from the source. Any retransmission delays at the Media Access Control (MAC) [25] [26] layer are also included. It is measured in the units of time (ms). Typically this can be calculated be dividing the difference of sent timestamp of the first packet and the receive timestamp of the last packet with the total number of packets received.

\subsection{Normalized Routing Load (NRL)}

The total number of routing packet transmitted per data packet defines the Normalized Routing Load (NRL). NRL is calculated by dividing the total number of routing protocol packets (ie: control packets) by the total number of data packets (ie: sent packets) from the source.

\section{LITERATURE REVIEW}

The literature reviewed in this section is selected in such a way that their scenarios remain similar and comparable. Figure 2 shows a typical scenario used in these papers.

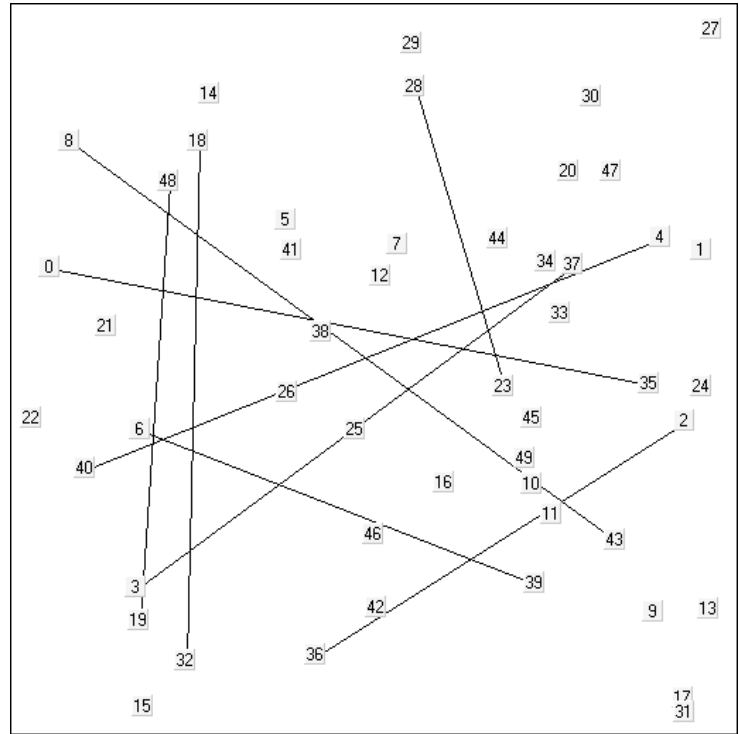

Fig 2: A Typical Scenario

\subsection{Comparison of AODV, ZRP and FSR Routing Protocols [30]}

In this paper, A. K. Maurya et. al., evaluate the AODV, ZRP and FSR protocols for scalable networks and simulated the three protocols to analyze the performance metrics in term of Packet Delivery Ratio (PDR), E2End delay, throughput and average Jitter, under the two different scenarios using Qualnet5.0 Simulator.

Table1. Simulation parameter for Scenario 1

\begin{tabular}{|l|l|}
\hline No. of mobile nodes & 50 \\
\hline Area Size & $1500 \mathrm{~m} \times 1500 \mathrm{~m}$ \\
\hline Minimum Speed & $10 \mathrm{~m} / \mathrm{s}$ \\
\hline Maximum Speed & $20 \mathrm{~m} / \mathrm{s}$ \\
\hline Total Simulation Time & $300 \mathrm{sec}$ \\
\hline Packet Size & 512 bytes \\
\hline Source Data Rate & 4 packets $/ \mathrm{sec}$ \\
\hline Node Position Strategy & Random \\
\hline Pause time & $\begin{array}{l}20,40,60,80 \text { and } 100 \\
\text { seconds }\end{array}$ \\
\hline No. of simulations & 15 \\
\hline
\end{tabular}

Scenarion-1 [30] comprises of a network with fixed number of nodes under randomized waypoint mobility model with varying pause times, simulation parameters are shown in Table 1. 
Table 2. Simulation parameter for Scenario 2

\begin{tabular}{|l|l|}
\hline No. of mobile nodes & $20,40,60,80,100$ \\
\hline Area Size & $1500 \mathrm{~m} \mathrm{X} 1500 \mathrm{~m}$ \\
\hline Minimum Speed & $10 \mathrm{~m} / \mathrm{s}$ \\
\hline Maximum Speed & $20 \mathrm{~m} / \mathrm{s}$ \\
\hline Total Simulation Time & $300 \mathrm{sec}$ \\
\hline Packet Size & $512 \mathrm{bytes}$ \\
\hline Source Data Rate & 4 packets $/ \mathrm{sec}$ \\
\hline Node Position Strategy & Random \\
\hline Pause time & $30 \mathrm{~seconds}$ \\
\hline No. of simulations & 15 \\
\hline
\end{tabular}

Scenarion-2 [30] comprises of varying number of nodes under the same randomized waypoint mobility model with a fixed pause time of 30 seconds as shown in Table 2.

The simulation results obtained in these two scenarios are as follows:

Packet Delivery Ratio: The packets delivery ratio of the AODV remains the best in contrast to the FSR and ZRP routing protocols. AODV delivered more than $60 \%$ of CBR packets in scenario1 and more than $80 \%$ packets in scenario 2 .

Average Throughput: In the three competing protocols the average throughput of AODV remains the best. It delivered more data packets in comparison to FSR and ZRP in both the scenarios.

Average End-to-End Delay: According to the simulation results the average end to end delay of FSR routing protocol remains the lowest in both scenarios.

\subsection{Comparison of AODV and DSR [31]}

In this paper, Y. Tan et. al., has focused on on-demand routing protocols such as "Ad-Hoc on Demand Distance Vector" (AODV) and 'Dynamic Source Routing" (DSR) protocols. Both routing protocols were simulated and the results were compared in terms of Packets Delivery Ratio, Average End to End Delay and Normalized Routing Load using NS2 Simulator [31]. The scenario parameters are defined in Table3. The simulation results are as follows:

Packet Delivery Ratio: The packet delivery ratio of both AODV and DSR protocols remained approximately same and was found in the range of $75 \%$ to $85 \%$

Normalized Routing Load: In terms of NRL, DSR always outperforms AODV even in stressful environments. This can be used on a cache strategy of DSR. Perhaps this is due to the caching of routes in the DSR protocol.

Average End-to-End Delay: The average end to end delay of the DSR protocol remains $30 \%$ to $50 \%$ higher than that of AODV protocol.
Table 3. The Parameters of the Scenario [31]

\begin{tabular}{|l|l|}
\hline No. of mobile nodes & 50 \\
\hline Area Size & $500 \mathrm{~m}$ X 500m \\
\hline Maximum speed & $20 \mathrm{~m} / \mathrm{s}$ \\
\hline Type of Traffic & CBR \\
\hline Packet Size & 512 bytes \\
\hline Source Data Rate & 4 packets/s \\
\hline No of Traffic sources & $10,20,30,40$ \\
\hline Total Simulation Time & $200 \mathrm{~s}$ \\
\hline Queue Size & 50 \\
\hline Pause time & $0 / 20 / 40 / 60 / 90 / 130 / 170 / 200$ \\
\hline
\end{tabular}

\subsection{Comparison of AODV, DSDV and RAODV Routing Protocols [32]}

In this paper, B. S. Gouda et. al., although focused on the study of energy consumption in various protocols, however other QoS parameters were also observed and can be taken into account for comparison with former papers in this section. For the sake of this purpose "Reverse Ad-Hoc On Demand Routing Protocols" (RAODV) and "Energy Reverse Ad-Hoc On Demand Routing Protocols" (ERAODV) are considered to be identical in behavior and will be referred to as RAODV only. The discrete event simulator NS2.34 was used for this simulation. The scenario parameters are summarized in Table 4.

Table 4. The Parameters of the Scenario [32]

\begin{tabular}{|l|l|}
\hline Queue Size & 50 \\
\hline Area Size & $800 \mathrm{~m} \mathrm{X} \mathrm{800m}$ \\
\hline Total Simulation Time & $110 \mathrm{~ms}$ \\
\hline Traffic & FTP \\
\hline Size of Packets & 1060 \\
\hline Number of Mobile & $5,15,25,35,45,55,65,75$, \\
Nodes & 85,95 \\
\hline Maximum speed & $10 \mathrm{~m} / \mathrm{s}$ \\
\hline
\end{tabular}

The simulation results obtained in this scenario are as follows:

Packets Delivery Ratio: Packet delivery ratio remain almost same for the three protocols studied in this paper.

Average Throughput: The average throughput of DSDV was found slightly lower and that of RAODV was found slightly higher than the average throughput of AODV protocol.

Normalized Routing Load: Normalized routing load of DSDV protocol remained almost one-third of AODV, while NRL of RAODV remained comparable to that of AODV.

Average End-to-End Delay: Average end to end delay of DSDV was found lower than both RAODV and AODV.

\section{CONCLUSION}

In this paper some of the leading literature regarding MANET routing protocols was surveyed and their Quality of Service 
(QoS) parameters were compared. Graphs in Figure 3 depict the performance analysis of various routing protocols. It is to be noted that the average end to end delay is shown as a relative quantity with respect to AODV which is taken as unit.
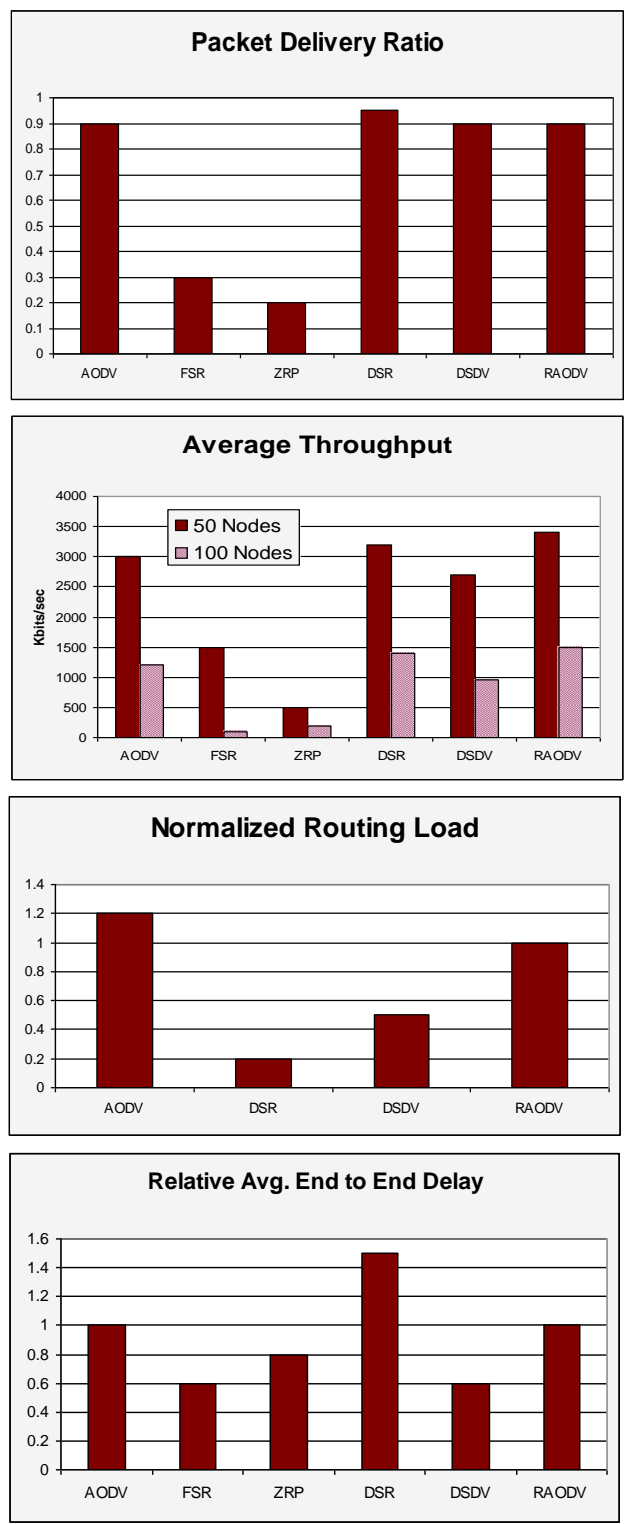

Fig 3: Comparision Graphs

Future work may include modifications in these protocols in order to adapt them to the requirements of the ad-hoc networks.

\section{REFERNCES}

[1] QualNet5.0. [Available Online] http://www.scalablenetworks.com

[2] Network Simulator [Available Online] http://www.isi.edu/nsnam/ns/ns-build.html

[3] Mohammadani, K.; Kazi, H.; Channa, I. \& Vasan, D. A survey on Integrated Wireless Network Architectures. International Journal of Computer Applications, 79(4), 49. (October 2013)
[4] M. K. Marina and S. R. Das "On-Demand Multi Path Distance Vector Routing in Ad Hoc Networks" in Proc. ICNP 2001, pp. 14-23, Nov. 2001.

[5] Zhi Li and Yu-Kwong Kwok, "A New Multipath Routing Approach to Enhancing TCP Security in Ad Hoc Wireless Networks" in Proc. ICPPW 2005.

[6] A. Nasipuri and S. R. Das, "On-Demand Multipath Routing for Mobile Ad Hoc Networks" Proc. ICCN 1999, pp. 64-70, Oct. 1999.

[7] BOUKERCHE, A., B. TURGT, N. AYDIN, M. Z AHMAD, L. BOLONI, D. TURGUT, Routing Protocols in Ad Hoc Networks: A Survey, Computer Networks, vol. 55, issue 13, Elsevier, 2011, pp. 30323080, DOI: 10.1016 .

[8] Rahman, J., Hasan, M., Mehedi, A., Islam, M., \& Ben, K. (2012, December). Comparative analysis the performance of AODV, DSDV and DSR routing protocols in wireless sensor network. In Electrical \& Computer Engineering (ICECE), 2012 7th International Conference on (pp. 283-286). IEEE

[9] Lal, C., Laxmi, V., \& Gaur, M. S. (2011, September). Performance analysis of MANET routing protocols for multimedia traffic. In Computer and Communication Technology (ICCCT), 2011 2nd International Conference on (pp. 595-600). IEEE

[10] SONG, J. H., V. W. S. WONG, V. LEUNG, Efficient On-Demand Routing for Mobile Ad Hoc Wireless Access Networks, IEEE Journal on Selected Areas in Communications, vol. 22, no. 7, 2004. pp. 1374-1383.

[11] GUPTA, A. K., H. SADAWARTI, A. K. VERMA, Performance Analysis of AODV, DSR and TORA Routing Protocols, IACSIT, vol. 2, no 2, 2010, pp. 226231.

[12] PARK, V., S. CORSON, Temporally-ordered Routing Algorithm Routing Protocol, IETF MANET vol. 03, June 2001.

[13]JIANG, M., J. LI, Y. C. TAY, Cluster Based Routing Protocol (CBRP), IETF MANET, July 1999.

[14] MISRA, S., S. K. DHURANDHER, M. S.OBAIDAT,A.NANGIA,N. BHARDWAJ, P GOYAL, S. AGGARWAL, Node Stability-Based Location Updating in Mobile Ad-Hoc Networks, IEEE Systems Journal, vol. 2, no. 2, 2008, pp. 237-277.

[15] MAAN, F., N. MAZHAR, MANET Routing Protocols vs Mobility Models: A Performance Evaluation, in Proceedings of IEEE Conference ICUFN 2011, pp. 179- 184, DOI: 978-1-4577-1177-0/11

[16] BAMIS, A., A. BOUKERCHE, I CHATZIGIANNAKIS, S. NIKOLETSEAS, A Mobility Aware Protocol Synthesis for Efficient Routing in Ad Hoc Mobile Networks, Computer Networks, vol. 52. Elsevier, 2008, pp. 130-154, DOI: 10.1016/jcomnet. 2007.09.023.

[17] PEI, G., M. GERLA, T. W. CHEN, Fisheye State Routing in Mobile Ad Hoc Networks, In Proceedings of the Workshops ICDCS 2000, Taipei, Taiwan, Apr. 2000, pp. D71- D78.

[18] MURTHY, S., J. G. ACEVES, An Efficient Routing Protocol for Wireless
Networks, ACM Mobile 
Networks and Applications Journal, Special Issue on Routing in Mobile Communication Networks, Oct. 1996, pp. 183-97.

[19] Haas, Zygmunt J., Marc R. Pearlman, and Prince Samar. "The zone routing protocol (ZRP) for ad hoc networks." (2002)

[20] Gouda, B. S. A Comparative Analysis of Energy Preservation Performance Metric for ERAODV, RAODV, AODV and DSDV Routing Protocols in MANET. International Journal of Computer Science \& Engineering Technology (IJCSET), 3, 516-524.

[21] Ramanathan, R., \& Steenstrup, M. 1998. Hierarchicallyorganized, multihop mobile wireless networks for quality-of-service support. Mobile networks and applications, 3(1), 101-119.

[22] Muir, A., \& Garcia-Luna-Aceves, J. J. 1998. An efficient packet sensing MAC protocol for wireless networks. Mobile Networks and Applications, 3(2), 221-234.

[23] Lee, S. B., \& Campbell, A. T. 1998. INSIGNIA: In-band signaling support for QoS in mobile ad hoc networks. In Proc of 5th International Workshop on Mobile Multimedia Communications (MoMuC, 98), Berlin, Germany.

[24] Razouqi, Q., Boushehri, A., Gaballah, M., \& Alsaleh, L. (2013, March). Extensive Simulation Performance Analysis for DSDV, DSR and AODV MANET Routing Protocols. In Advanced Information Networking and Applications Workshops (WAINA), 2013 27th International Conference on (pp. 335-342). IEEE.

[25]Tuteja, A., Gujral, R., \& Thalia, S. (2010, June). Comparative Performance Analysis of DSDV, AODV and DSR Routing Protocols in MANET Using NS2. In Advances in Computer Engineering (ACE), 2010 International Conference on (pp. 330-333). IEEE.

[26] Lakshmikanth, G., Gaiwak, M. A., \& Vyavahare, P. D. (2008, November). Simulation based comparative performance analysis of adhoc routing protocols. In TENCON 2008-2008 IEEE Region 10 Conference (pp. 1-5). IEEE

[27] Clausen, Thomas, Brian Adamson, and Christopher Dearlove. "Jitter considerations in mobile ad hoc networks (MANETs)." (2008).

[28] Tan, Y., Song, Y., \& Zhou, S. (2011, July). Simulation based comparative performance analysis of on-demand routing protocols. In Smart and Sustainable City (ICSSC 2011), IET International Conference on (pp. 1-5). IET.

[29] Khoriba, G. A. A. M. (2010). Mobility-aware energyefficient protocols for Wireless Ad hoc Networks.

[30] Maurya, A. K., \& Singh, D. (2010). Simulation based Performance Comparison of AODV, FSR and ZRP Routing Protocols in MANET. International Journal of Computer Applications, 12(2).

[31] Tan, Y., Song, Y., \& Zhou, S. (2011, July). Simulation based comparative performance analysis of on-demand routing protocols. In Smart and Sustainable City (ICSSC 2011), IET International Conference on (pp. 1-5). IET.

[32] Gouda, B. S., Mandai, A. B., \& Narayana, K. L. (2012, October). Simulation and comparative analysis of energy conservation performance metric for ERAODV, AODV and DSDV routing protocols in MANET. In Information and Communication Technologies (WICT), 2012 World Congress on (pp. 278-282). IEEE

[33] Vasan, D., Kazi, H., Channa, I., Mohammadani, K. H. \& Shaikh, A. (2013, Dec). A Survey Of Routing Protocols Performance Simulated In Different Scenarios With Different Simulators. In International Journal of Wireless Communication Networks (IJWCN 2013).

[34] Shaikh, A. \& Faizullah, S. (1999, Jun). A FeedbackBased UPC Parameters Renegotiation Strategy for ATM Networks. In Proceedings of International Conference on Parallel and Distributed Processing Techniques and Applications (PDPTA 1999) pp. 937-943. 